\title{
Urban digital simulators as knowledge catalysts: a case study on the soundscape of Rio de Janeiro city center
}

\section{SIGRADI2018 TECHNOPOLITICAS \\ xxii congresso da sociedade iberoamericana de gráfica digital 22th conference of the iberoamerican society of digital graphics 07|08|09|novembro|2018 iau usp | são carlos | sp br}

\author{
Marcio Nisenbaum \\ Universidade Federal do Rio de Janeiro | Brazil | marcio.nisen@gmail.com \\ Naylor Vilas Boas \\ Universidade Federal do Rio de Janeiro | Brazil | naylor.vilasboas@ufrj.br \\ José Ripper Kós \\ Universidade Federal do Rio de Janeiro | Brazil | josekos@ufrj.br
}

\begin{abstract}
This paper discusses about urban digital simulators, focusing on soundscape representation aided by game engines. Digital modelling techniques have evolved and new approaches emerged, offering novel ways of experiencing the digital realm. Within soundscapes studies, the videogame media and the game design process offer interesting ways of dealing with sound phenomena, space and time. This paper describes a prototype, as part of an ongoing lab research, that simulates the soundscape of a specific site in Rio de Janeiro using game engine technology,
\end{abstract}

Keywords: Simulator; Sound landscape; Soundscape; Video game.

\section{INTRODUÇÃO}

A cidade que se apresenta a nós cotidianamente pode ser entendida como um complexo fenômeno, formado por camadas de informação que se inter-relacionam em seus diferentes espaços, por sua vez inscritos em múltiplas temporalidades que se entrelaçam na trama do tempo histórico (Ascher, 1998). Definida dessa forma, a cidade, inapreensível em toda a sua complexidade, se faz de esfinge, e convida quem busca sua compreensão a decifrá-la.

O desafio da representação gráfica das cidades necessariamente se confronta com a impossibilidade da apreensão de qualquer totalidade do ambiente urbano. Avanços recentes no campo da análise e representação de dados estão abrindo promissores caminhos de olhar a cidade por novos pontos de vista (Aguiar \& Netto, 2012), ampliando os modos de aproximação a ela. No entanto, sempre serão um recorte possível de uma totalidade mais ampla em constante processo de transformação. Assim, entender a cidade como um fenômeno inscrito no espaço e no tempo, logo um fenômeno também em movimento, apresenta desafios à gráfica digital na medida em que suas simultaneidades, transversalidades, multiplicidades, entre outros atributos da cidade contemporânea (Gausa et al., 2001) passam a ser fundamentais como objetos de representação.

Pensar a representação da cidade como espaço de construção coletiva de conhecimento caracteriza as pesquisas do Laboratório de Análise Urbana e Representação Digital (LAURD) da Universidade Federal do Rio de Janeiro, desde sua criação. Ao longo do tempo, diferentes estudos urbanos foram realizados tendo como base os modelos digitais tridimensionais da área central da cidade desenvolvidos pelo laboratório, entendidos como uma base de dados que armazena, articula e catalisa o conhecimento que vem sendo construído ao longo do tempo pelos pesquisadores.

O atual campo de estudo do grupo de pesquisa volta-se para a articulação dos seus modelos digitais com o campo dos videogames, explorando as possibilidades abertas pela representação dinâmica do movimento no espaço e no tempo, que tais ferramentas oferecem. Tais explorações atualmente se materializam no desenvolvimento de um simulador urbano digital (chamado "SIMRio") que permite a viagem temporal entre diferentes momentos de uma determinada área do Rio de Janeiro, demonstrando uma abordagem metodológica possível de estudar a cidade. Ao levar os modelos digitais do laboratório para um novo campo de possibilidades, e de novas complexidades, a construção do simulador amplia as capacidades de estudar aspectos da cidade pouco explorados anteriormente.

Esse é o caso do estudo de paisagens sonoras, campo que investiga a experiência de ambientes sonoros - sons audíveis em um determinado espaço e tempo. A dinâmica desse campo demanda uma leitura da cidade baseada na ideia de eventos, acontecimentos e transformações que transcendem a mera descrição da sua massa edificada. A representação de sons da cidade por meio de videogames beneficia-se da natureza procedural dessa mídia e de sua capacidade de processar informação a partir de comportamentos dinâmicos e emergentes, o que contribui para novas formas de compreensão do fenômeno sonoro na cidade.

Propomos aqui expor os resultados da simulação de paisagens sonoras em um recorte específico, por meio do 
uso do motor de jogo Unity. Além de materializar o processo de pesquisa, a elaboração do simulador demonstra, sobretudo, sua capacidade de catalisar novos conhecimentos sobre a cidade a partir de sua dimensão sonora.

\section{MODELOS DIGITAIS E VIDEOGAMES}

É importante inicialmente enfatizar que a utilização de modelos digitais em pesquisas urbanas, que permeia os estudos no âmbito do laboratório, deve ser compreendida como uma ferramenta de análise e reflexão, que registra um processo de construção de conhecimento sobre a arquitetura e a cidade. Considera-se assim que o "mundo digital" gerado por modelos seria um "[...] espaço de articulação, validação e potencialização das informações documentais que circulam em uma pesquisa". (Vilas Boas, 2010, p.05)

Saldaña (2014, p. 05) argumenta que o uso de modelos tridimensionais em processos de pesquisa de rigor científico se justifica ao preencher alguns dos seguintes critérios: (i) o modelo provoca "insights" que não surgiriam sem ele; (ii) o modelo demonstra evidências que sustentam ou refutam uma hipótese; (iii) o modelo conecta diferentes tipos de informação de forma que se torna mais fácil interrogar e analisar os dados; (iv) o processo de elaboração do modelo ajuda a entender o material analisado.

No que se refere a estudos historiográficos, Kós (2003, p.65), argumenta que modelos podem funcionar como ferramentas de convergência de informações a um local, permitindo a sobreposição de diferentes dados relacionados a um determinado território, o que confere uma característica de sistema ao processo de representação.

Muitas das metodologias que exploram modelos $3 d$ se baseiam em sistemas de simulação, e desenvolveram-se a partir de técnicas do campo da computação gráfica como a gramática da forma e os L-Systems, sistemas que se definem a partir de regras simples e geram "outputs" complexos. Essa lógica alimentou também o desenvolvimento do campo dos games, que partilham dessa mesma subestrutura procedural - o que fica bem claro em jogos como "Game of Life" e "Sim City".

No caso de jogos eletrônicos, para além da representação de sólidos geométricos e cenários, a possibilidade de simulação da própria experiência de interação com os modelos digitais o torna uma ferramenta singular. A representação nesse caso emerge tanto das condições do sistema e suas regras quanto das decisões do usuário, tornando a experiência de jogo um espaço de observação fenomenológica. Assim, quando tratamos de videogames é importante analisar tanto o processo de "game design" - onde estabelecem-se as regras, condições, cenários e referências simbólicas. - quanto o próprio ato de jogar, quando todos esses elementos passam a fazer sentido e constroem o "mundo simulado".

Nesse contexto, é importante compreender o funcionamento dos chamados motores de jogos, que possibilitaram reunir em um ambiente diferentes processos de trabalho envolvidos na criação de um jogo. O termo "motor de jogo" (traduzido de "game engine") surgiu na década de 90, ao mesmo tempo que surgiam os primeiros jogos de atirador em primeira pessoa ("Firstperson shooter"). Esses jogos, e outros subsequentes, como "Quake" e "Unreal", foram desenvolvidos de forma a separar o conteúdo específico do jogo da plataforma que processa suas informações e regras. Assim, os jogos que anteriormente eram criados como entidades singulares passaram a ser aproveitados em diferentes produções.

Para Passos et al. (2009, p.4) um motor de jogo pode ser considerado como tal quando oferece um sistema de renderização $3 \mathrm{~d}$ com suporte a materiais customizáveis, um sistema de simulação física, uma arquitetura que suporte programação, um editor de cenas, e a capacidade de importar arquivos externos como modelos, imagens e áudio de outros softwares. Além disso, devem possibilitar a "saída" em formato múltiplos como jogos para PC, consoles, celulares etc. Podemos interpretar o motor de jogo, dessa maneira, como um gerenciador de sistemas e recursos que produz mídias audiovisuais em diferentes formatos.

Nos últimos anos, o avanço tecnológico dos "game engines" e a maior capacidade de processamento computacional sofisticou a produção dos videogames, tornando os gráficos e efeitos sonoros mais convincentes e realistas. Ainda, temos hoje o renovado interesse pela mídia da Realidade Virtual, formato que pode ser facilmente produzido por meio do motor de jogo, já integrado aos diferentes aparatos como os óculos Rift, HTC Vive etc.

Cury (2008, p.16) ressalta que para além das possibilidades de representação cada vez mais atraentes, o potencial maior de uso de motores de jogos, em se tratando de arquitetura e urbanismo, transcende o paradigma do fotorrealismo, destacando a "[...] possibilidade de inclusão de elementos climáticos, de eventos disparados pela proximidade do usuário, de agentes controlados pelo computador [...]".

Essas observações ilustram as intenções de exploração desses instrumentos no âmbito do laboratório. No caso específico do simulador idealizado, o motor assume um papel de gerenciador de informações e experiências, possibilitando a organização de dados temporais (vinculados aos edifícios) e a experimentação por meio do movimento, configurando um sistema que permite a navegação espaço-temporal na cidade.

\section{O SIMULADOR URBANO DO RIO DE JANEIRO}

A ideia de criar um simulador urbano no contexto de pesquisas do laboratório representou uma mudança epistemológica na maneira de pensar seus instrumentos e métodos, na medida em que o motor do jogo se apresenta como um espaço digital de mediação que lida com tempo, movimento e comportamentos. Além de atender aos anseios da pesquisa, o interesse por videogames decorre também do reconhecimento deste campo como uma área de pesquisa relevante, com bases teóricas cada vez mais sólidas e um repertório semiológico cada vez mais conhecido, utilizado e familiar. 
Na primeira fase da pesquisa (2012-2015), foi elaborado um protótipo englobando a área do Largo da Carioca, no centro do Rio de Janeiro, de modo a representar suas transformações nos últimos cem anos. A modelagem dos detalhes arquitetônicos históricos pôde ser feita com base em mapas, fotos e outros documentos históricos, o que permitiu a recriação, por exemplo, do chafariz da Carioca e do hospital da Ordem Terceira da Penitência edificações que já não existem mais na paisagem atual do Largo.

Evidenciou-se, nesse contexto, a importância da ferramenta como instrumento de representação do espaço-tempo, combinada com o descobrimento do espaço por meio da movimentação. Conceitualmente, o motor de jogo passou a ser encarado como uma máquina do tempo, que pode processar informações históricas diversas e gerar cenários com configurações particulares.

\section{O LARGO DE SÃO FRANCISCO}

A experimentação com o Largo da Carioca trouxe resultados relevantes mas indicou a necessidade de uma organização metodológica mais rígida em relação ao uso de motores de jogos, lançando bases para a segunda fase da pesquisa (2015-2018). O interesse então se voltou para o espaço do Largo de São Francisco de Paula, também no centro do Rio de Janeiro. A escolha pelo Largo ocorreu em um contexto de estudos sobre a ideia de centralidades urbanas no centro do Rio de Janeiro, à luz da obra de Sisson "Espaço e Poder: os três centros do Rio de Janeiro.

Embora o Largo não fosse necessariamente uma das centralidades abordadas pelo autor em questão, o espaço, no âmbito da pesquisa, foi considerado uma área relevante a ser explorada, que manteve sua tipologia de praça em meio a todas as transformações ocorridas na área. O Largo ainda apresenta edificações de valor histórico como por exemplo a Igreja São Francisco de Paula, construída no final do século XVIII, o edifício do Instituto de Filosofia e Ciências Sociais da UFRJ, além do Real Gabinete Português de Leitura, que se encontra nas proximidades.

O estado atual de desenvolvimento da pesquisa contempla a representação de diferentes momentos históricos do Largo, podendo-se transitar entre esses tempos e verificar as mudanças ocorridas na cidade. Como períodos mais detalhados, temos, além da representação da sua condição atual, sua reconstrução referente ao ano de 1870. Além desses dois períodos, elaborou-se também um cenário hipotético buscando representar o edifício-fita desenvolvido por Le Corbusier na década de 1930, de modo a verificar sua influência visual no espaço do Largo.

O uso de modelos digitais no contexto de pesquisa do laboratório, como já comentado, é de longa data. Contudo, a geometria simulada e o processamento em tempo real nos motores de jogos exigem novas formas de fluxo de trabalho e operacionalização. A complexidade envolvida na elaboração do simulador demandou a divisão do laboratório em equipes que cuidam de procedimentos diversos como modelagem, programação, conteúdo, interface etc. Em termos de métodos, os modelos a serem processados no motor de jogo não podem possuir muitos polígonos, o que leva a adoção da chamada modelagem "low-poly". Nesse processo, deve haver uma preocupação para que a simplificação das formas não reduza a iconicidade dos modelos representados. Outros artifícios consistem em utilizar menos mapas e recursos que precisam ser carregados durante o jogo.

Uma metodologia recorrente na organização de modelos complexos é a utilização de módulos. Segundo Jones (2011, p.07), a modularidade é o processo de reutilização do mesmo objeto em uma cena, o que significa que a partir da existência de apenas um módulo pode-se complexificar o ambiente a partir de sua repetição, deformação etc. No caso da modelagem do Largo de São Francisco, a modelagem mais tradicional foi decomposta em módulos menores e texturizados.

Uma das questões problematizadas no contexto da pesquisa é a representação da passagem do tempo. $O$ tempo em um motor de jogo é uma variável que pode ser configurada e manipulada de diferentes formas. Podemos pausar, acelerar e criar eventos condicionados à sua passagem.

A noção do tempo no jogo também pode ser compreendida à luz da ideia de estados, descrita por Juul (2006). Em sua visão, o jogo funciona como uma máquina de estados, que a cada momento explicita uma determinada configuração espacial e um "set" de comportamentos e relações que determinam acontecimentos. Fases em videogames são exemplos destes estados, e a transição entre elas pode representar variações temporais em diferentes escalas cronológicas.

No caso do simulador, a mudança de estado representa especificamente uma transição temporal, que se expressa por meio de transformações estruturais no espaço urbano (edifícios, ruas etc.). Percebe-se nesse contexto a importância do tempo como variável que determina o comportamento do sistema.

\section{A PAISAGEM SONORA DO LARGO DE SÃO FRANCISCO}

Antes de descrever a metodologia elaborada a partir do motor de jogo é necessário discutir algumas definições sobre a ideia de paisagem sonora.

\section{UM MAPEAMENTO TEÓRICO}

A autoria do termo "soundscape" (que deriva de "landscape" e é traduzido como paisagem sonora) atribuída à Murray Schafer é discutível, mas é na obra do compositor canadense intitulada "The soundscape: our sonic environment and the tuning of the world", de 1977 , que a palavra de fato ganhou reconhecimento e as bases teóricas do campo foram lançadas. A obra de Schafer fez parte do "World Soundscape Project", um projeto que se iniciou no final da década de 1960 na Simon Fraser University, no Canadá, e deixou como legado uma série de gravações, artigos e publicações que contribuíram para a consolidação do estudo das paisagens sonoras, campo também chamado por alguns autores de "Acústica Ecológica".
3 
Uma noção fundamental que ajuda a estruturar este conceito é a ideia de ambiente acústico ("acoustic environment") ou ambiente sonoro ("sound/sonic environment"). O uso do termo "ambiente" indica um componente espacial, significando "[..] aquilo que cerca ou envolve os seres vivos ou as coisas; meio ambiente", ou então "Lugar, sítio, espaço, recinto" (Ferreira, 2004).

Brown et al. (2016, p. 2) definem ambiente acústico de um local como o "som de todas as fontes que podem ser ouvidas por alguém neste lugar". O ambiente acústico seria desta forma produzido pela existência de fontes e suas localizações, assim como por alterações causadas no "caminho" do som até o ouvinte, como as reflexões, absorções, atenuações etc. de acordo com as características físicas do espaço.

É importante constatar que independentemente do local e escala, o ambiente acústico existe a partir das relações de suas variáveis, que seriam as fontes sonoras, a localização, a movimentação do receptor e as condições de propagação. Dessa forma, terá sua configuração alterada em função de várias circunstâncias como o dia, horário, estação etc. (Brown et al. 2016, p.02), configurando um espaço sonoro dinâmico e mutante, derivado dos aspectos físicos do ambiente, mas também de um sistema de relações.

A construção da ideia de paisagem sonora está intimamente relacionada à compreensão de ambiente sonoro. Brown et al. (2016, p.05) definem paisagem sonora como "[...] o resultado da construção perceptiva do ambiente acústico". Depreende-se desta definição que a ideia de paisagem sonora nasce da experiência dos ambientes acústicos. Nesta mesma linha, o "Handbook for Acoustic Ecology" de Barry Truax, expõe "soundscape" como: "[...] Um ambiente de som (ou ambiente sonoro) com ênfase na maneira como é percebido e entendido por um indivíduo, ou pela sociedade. Depende, portanto, da relação entre 0 indivíduo e o ambiente em si." (Truax, 1999).

Verifica-se que a definição de Truax se assemelha a de Brown et al. (2016) ao enfatizar o processo de percepção como elemento que "molda" a paisagem, emergindo da relação do indivíduo com o ambiente. Já Schafer traz uma leitura semelhante e dá ênfase ao processo midiático envolvido na compreensão de paisagem sonora: "[...] Tecnicamente, qualquer parte do ambiente sonoro entendido como um campo de estudo. O termo pode referir-se a ambientes reais, ou construções abstratas como composições musicais e montagens de fita, especialmente quando consideradas um ambiente." (Schafer, Glossário, 1994/1977).

Uma questão também fundamental relacionada à compreensão de "soundscapes" é a ideia da experiência ao longo do tempo, que é representada pelo evento sonoro, noção trabalhada inicialmente por Michael Southworth (1967) a partir de seus mapas sonoros e também explorada por Schafer. O termo "evento" remete à ideia de acontecimento sonoro - o som que ocorre em algum lugar, durante um intervalo temporal e por alguma causa. A construção da ideia de paisagem sonora a partir de eventos sonoros baseia-se assim em um sistema de relações no espaço-tempo, em oposição a uma visão espacial estática do ambiente sonoro.

\section{REPRESENTAÇÃO DE PAISAGENS SONORAS}

O processo de mediação de paisagens sonoras é um campo de grande interesse, que gera debates desde o World Soundscape Project até os dias de hoje. Schafer (1994/1977, part. 3, cap.2) argumenta que: "[...] gerar uma imagem convincente de uma paisagem sonora envolveria muita técnica e paciência: milhares de gravações deveriam ser feitas; milhares de medições realizadas: e novas formas de descrição deveriam ser desenvolvidas."

O autor chama de Sonografia a "arte da notação de paisagens sonoras", que incluiria os métodos recorrentes de registro sonoro como oscilogramas, a medição de níveis de pressão sonora assim como processos cartográficos que relacionam intensidades ou eventos sonoros a sistemas geográficos. A produção de mapas, especificamente, configura o que alguns autores chamam de Cartografia Sonora (Niemeyer \& Rego, 2014) e sua compreensão é fundamental em estudos de ambientes sonoros. Neste campo, em linhas gerais, pode-se identificar dois processos de representação cartográfica: o mapa que representa a média de intensidade sonora em uma determinada área; e outro que busca identificar os aspectos qualitativos de sons, normalmente por meio da identificação de eventos sonoros.

O mapa de ruídos, ou acústicos, tem sido um instrumento recorrente no estudo da poluição sonora e de estratégias de contenção. Embora sua utilização tenha se intensificado nos últimos anos, este tipo de mapa já existe há muito tempo, e era no passado conhecido como "Isobel", quando se assemelhava a mapas topográficos e era medido manualmente. Tais representações exibiam a média de intensidade sonora captada por sonômetros em um recorte estabelecido, indicando a distribuição do som no espaço analisado. $\mathrm{Na}$ Comunidade Europeia, a elaboração de mapas de ruídos é exigida através da diretiva 2002/49/CE, de junho de 2002, e leva em conta ruídos provenientes de tráfego rodoviário, tráfego ferroviário, aeroportos, e instalações de atividade industrial, incluindo portos.

Mapas sonoros, diferentemente de mapas de ruídos, buscam representar outros atributos do som e expor julgamentos mais subjetivos. Desta maneira, esses mapas são normalmente considerados ferramentas de análise específicas do campo da Acústica Ecológica. Kang et al. (2016, p.289) coloca que: "Em estudos envolvendo paisagens sonoras, todo o espectro sonoro perceptível em um contexto é normalmente considerado. Assim, pesquisadores de paisagens sonoras estão em busca da ampliação do processo de mapeamento de modo a processar outras fontes, tanto positivas quanto negativas."

Enquanto em mapas de ruídos a apresentação é padronizada, as possibilidades de mapeamento e representação de paisagens sonoras são múltiplas e híbridas, constituindo um campo aberto a experimentações. Alguns autores como Signorelli (2015) apontam potenciais no uso de mídias digitais como o videogame no processo de representação de paisagens 
sonoras em oposição à mídia cartográfica. Estudos envolvendo auralização também começam a se interessar por este tipo de representação de modo a tornar possível a representação do estímulo sonoro em função do movimento. Além disso, a compreensão do ambiente sonoro como um sistema encontra no motor de jogo um espaço de sistematização e definição de regras que permite ir além dos mapas sonoros.

\section{O GAME DESIGN SONORO}

Em seu livro "Rules of Play: Game design fundamentals", Zimmerman e Salen (2014) discutem sobre a singularidade midiática de jogos a partir da ideia de representação procedural. Para os autores, esta forma de mediação transcende a significação por meio de referências audiovisuais, contemplando processos, comportamentos e relações condicionadas a partir de regras estabelecidas pela mídia, e desestabilizadas no processo de interação com o jogador. Desta forma, a representação em videogames emerge tanto das condições e estrutura formal definidas no processo de game design quanto do momento de fruição do ambiente virtual.

A compreensão dessas questões se reflete na forma como o ambiente sonoro é representado por meio da mídia do jogo eletrônico. Podemos inicialmente argumentar que a representação sonora por meio do jogo é de fato um processo de Design, já que contempla uma série de procedimentos - planejamento, envolvimento, mapeamento, definição de regras e outros. Em relação ao uso específico do termo Design Sonoro, cabe lembrar que essa terminologia descreve as práticas em produções audiovisuais como o cinema, e até os dias de hoje, se referem ao processo compositivo da escolha de trilha sonora, efeitos, dublagem etc.

A apropriação deste termo no campo de jogos eletrônicos explicita uma diferença fundamental entre as mídias, quando a lógica compositiva dos filmes contrasta com a ideia de simulação e performance inerente aos videogames. Uma das principais diferenças dessas mídias, que se reflete no processo de design, é a questão da linearidade. Segundo Shum (2008, p.98), em um formato linear, como filme, a organização temporal do áudio é predeterminada pelo "sound designer", buscando acompanhar a narrativa imagética existente. Já em um ambiente não-linear, como um jogo, a paisagem sonora resultante se forma por meio do movimento do jogador, o que implica no planejamento de possíveis "potenciais" paisagens sonoras que poderão emergir por meio da interação.

Uma abordagem que auxilia a compreensão de paisagens sonoras em games é a proposta por Grimshaw (2007), que defende que o jogador constrói o ambiente acústico dinamicamente - a partir de um sistema de relações e não somente como uma sequência de sons no tempo. O motor de jogo nesse contexto é o palco do que - autor chama de ecologia acústica (um sistema composto de sons e outros recursos sonoros gerenciados por meio de scripts) que define as relações do jogador com o áudio permitindo liberdade, improvisação e múltiplas narrativas sonoras.
Este tipo de visão inspira o conceito de áudio procedural que figura no desenvolvimento de muitos jogos contemporâneos, em oposição à lógica compositiva tradicional. Collins (2009, p. 05) alega que essa visão na verdade sempre existiu, mas torna-se cada vez mais interessante na medida que os jogos se complexificam e demandam um maior dinamismo sonoro. Farnell (2007, p.01) propõe uma visão semelhante, enfatizando o entendimento do som como um processo e não um produto. O áudio procedural em seu entendimento pode ser compreendido como uma máquina que tem relações parametrizadas, sendo que o som nasce dessas relações de forma processual, e não a partir da leitura de dados digitais fixos.

No caso da simulação da paisagem sonora do Largo de São Francisco, o que parece mais interessante dessa abordagem seria a transição de uma visão sobre a paisagem sonora da cidade a partir da ideia de composição, para uma visão mais sistemática, onde os sons derivam de regras e o resultado varia a cada jogo.

Um passo conceitual importante em nossa pesquisa foi a busca por essas relações e regras nas próprias condições estruturais e espaciais da cidade. Esse processo exige analisar, além da configuração espacial urbana, a compreensão dos usos dos espaços e os eventos que potencialmente podem ocorrer em função de tipologias do recorte estudado. Essa ideia "alimenta" a descrição do protótipo que apresentamos neste artigo.

O processo de design, nesse contexto, passa a exigir uma cartografia sonora cujo processo de elaboração não ocorre apenas por meio do rastreamento de sons e emissores sonoros, mas pela identificação de potenciais fontes que dependem das condições da cidade. Nesse sentido, o mapa sonoro que traz informações para o jogo - fruto desta observação de relações e comportamentos é um mapa de possibilidades que se materializa no "gameplay".

\section{METODOLOGIA}

A discussão sobre a mídia do jogo e suas particularidades lançou as bases para a elaboração de uma metodologia de construção de paisagens sonoras baseada na natureza representacional de videogames. Pode-se dizer que nesse processo de "tradução" semiológica, emergiu um novo olhar acerca da própria ideia de ambiente acústico, e consequentemente paisagem sonora, inspirado na natureza sistemática de jogos e no ato de jogar.

Considerando a premissa de que paisagem sonora é resultado da experiência de um sistema emergente, que é o ambiente sonoro, é necessário agora descrever o funcionamento deste em âmbito digital, suas partes e sua operação, assim como criar parâmetros que controlem seu comportamento no mundo do motor de jogo.

No ambiente do jogo, por meio da programação, podemos pensar de fato no protótipo como um sistema, baseado em regras e relações definidas por códigos. Em termos de programação sonora em games é muito comum o uso de condicionantes (if/then) para determinar o comportamento dos sons. No caso do simulador, através da programação pudemos "materializar" a ideia

5 
discutida de evento sonoro, a partir de um script que controla o comportamento de um objeto sonoro, conferindo parâmetros de controle e permitindo sua interação com outros eventos ao mesmo tempo.

No que se refere à lógica da simulação, o evento sonoro seria controlado pelas variáveis (i) tipo de som (ou timbre, que seria a faixa sonora em si), (ii) sua repetição (ritmo) e (iii) localização no ambiente do jogo. Alterando-se estas variáveis, novas combinações sonoras emergem no espaço-tempo.

Para que a localização desses eventos pudesse ser manipulável, idealizamos o objeto "tipo sonoro" (Figura 1) que funciona como um indicador de tipologias sonoras e pode ser associado aos objetos do sistema. Isso permitiu relacionar os eventos sonoros à configuração espacial e tipológica da cidade, "espacializando" esses elementos em função das condições do recorte urbano estudado.

Podemos neste contexto resgatar a ideia da máquina de estados de Juul (2006) e a partir dela criar o termo "estado sonoro" para descrever essa configuração sonora específica formada a partir dos "tipos sonoros" e consequentes eventos sonoros disparados. Alterações no espaço e na frequência dos eventos sonoros produzem novos "estados sonoros", que podem representar as transformações da paisagem sonora ao longo do tempo, por exemplo (anos, horas etc.).

Em termos de operacionalização, o script que controla os eventos sonoros carrega clipes de áudio de uma pasta e toca de maneira aleatória, respeitando os parâmetros de intervalo temporal que podem ser informados pelo usuário ou determinados por alguma variável pública. Isso permite "parametrizar" a repetição do som (e alternância), possibilitando a manipulação de seu comportamento no tempo. Os "tipos sonoros", que relacionam eventos sonoros à estrutura da cidade, funcionam como "disparadores" de sons em função das tipologias urbanas. Eles possibilitam vincular diferentes eventos sonoros a uma entidade que pode ser espalhada pela cena e conectada aos objetos (edifícios, árvores, bancos etc.).

Ainda como parte do protótipo e elemento fundamental do processo de representação, a estruturação da interface cria as condições de interação com o usuário, que irá "construir" sua própria interpretação da paisagem ao explorar a ferramenta. Por meio da interface o "designer" pode também induzir determinadas visões sobre o sistema por meio de filtros que direcionam informações e simulam comportamentos.

A possibilidade de se ter controladores para manipular os eventos sonoros permite explorar combinações hipotéticas e testar diferentes sonoridades que não necessariamente existem como cenários sonoros observados em campo. Essa liberdade contribui para uma maior sensibilização em relação aos sons existentes e para a análise isolada de cada evento sonoro.

\section{REPRESENTAÇÃO DE DIFERENTES TEMPOS}

A partir da definição do sistema que gerencia o ambiente sonoro no motor de jogo, experimentações foram feitas de modo a contribuir com o protótipo desenvolvido no

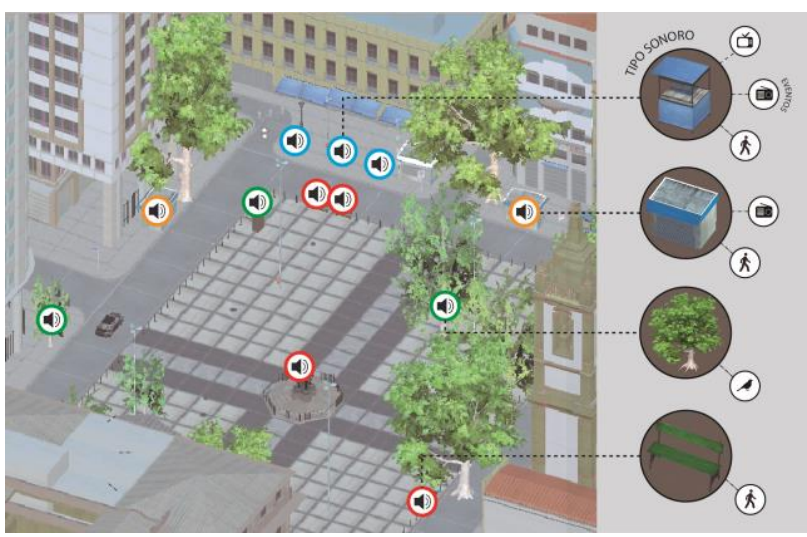

Figura 1: Tipos sonoros representando a espacialização. Fonte: autoral.

âmbito do laboratório. Vale ressaltar que uma vez estabelecida a lógica de funcionamento do sistema, o trabalho subsequente se refere à definição dos "tipos sonoros", sua vinculação aos objetos presentes no recorte estudado (promovendo assim sua espacialização) e a definição dos parâmetros dos scripts sonoros (Figura 02).

No que se refere à representação do Largo tal como ele é hoje em dia, uma etapa fundamental é a visita de campo, quando pode ser feita a observação de diferentes tipologias e usos do espaço. Esse registro é feito por meio de um mapa, que orienta o posicionamento e vinculação dos "tipos sonoros" em função das estruturas sonoras observadas. As informações são então transferidas para o motor de jogo por meio da definição de "prefabs" e scripts.

Neste contexto, vale destacar a importância das gravações, que permitem o registro de sonoridades a serem avaliadas por meio de oscilogramas e

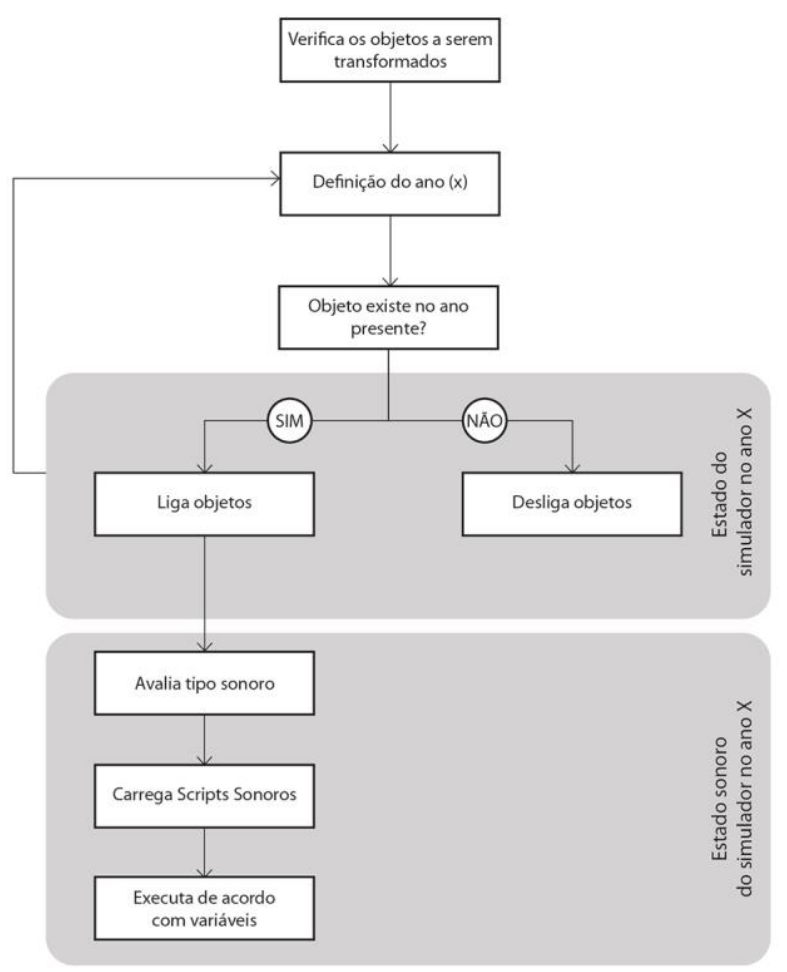

Figura 2: Esquema representando os estados sonoros. Fonte: autoral. 
espectrogramas. Nem sempre em campo identificamos ou nos damos conta da presença de alguns eventos sonoros, e as gravações e "visualizações" digitais podem ajudar neste sentido. Além disso, por meio da análise destes elementos gráficos podemos criar métodos de calibragem, definindo o intervalo temporal entre a repetição dos eventos e assim conferindo o ritmo ao ambiente virtual.

O funcionamento do sistema e a grande quantidade de faixas sonoras disponíveis em bancos de áudio - muitas vezes sintetizadas - possibilitam a recriação de paisagens sonoras de diferentes tempos históricos ou até mesmo a predição de novos ambientes sonoros em função de transformações urbanas. No contexto da pesquisa, a modelagem histórica da estrutura física da cidade, como já colocado, foi feita com base em mapas e registros iconográficos. Para a representação do ano de 1870, especificamente, cruzou-se dois mapas elaborados na época, com poucos anos de diferença, sendo que um deles continha as informações necessárias para a modelagem das fachadas dos edifícios dentro do recorte estudado.

No que se refere à representação de sons, o processo difere significativamente da pesquisa morfológica, pois além de se considerar a massa física da cidade, é importante compreender sua dinâmica, eventos e acontecimentos. A representação de paisagens sonoras que não existem mais obviamente esbarra na impossibilidade de visita a campo, que permitiria essa compreensão. Neste sentido, há obviamente lacunas que dão margens a interpretações e suposições de forma que se construa um ambiente sonoro "aberto", que pode sofrer mudanças na medida que novas descobertas são feitas.

É importante também ressaltar que encontramos poucas referências de reconstituições de paisagens sonoras no âmbito de estudos urbanos. No campo envolvendo auralização, a maior parte das pesquisas encontradas, que consideram o som em seu aspecto histórico se referem a modelagem acústica, reconstituições do comportamento sonoro em função das estruturas físicas das cidades históricas e também de seus interiores, como visto em auralizações de igrejas e teatros antigos. Este campo é chamado por alguns autores de "Archaeoacoustics", e se insere na área de pesquisa do Patrimônio Digital (Scarre and Lawson, 2006 apud Murphy, D. et al.).

Os novos métodos de cálculo computacional de fato possibilitaram o desenvolvimento de técnicas de auralização bem precisas, podendo-se ter uma boa noção de como os sítios arqueológicos moldavam o som de maneira particular, sendo possível escutar o sinal sonoro e todo seu processo de propagação corretamente. Algumas pesquisas são referências nesse campo como a de Aaron Watson, que investigou a acústica de diversos sítios arqueológicos, incluindo o StoneHenge.

Entretanto, questiona-se nesses casos a redução da ideia de evento sonoro - que carrega informação sobre um acontecimento - ao estudo exclusivo do sinal sonoro, desvinculado muitas vezes do que realmente ocorre no local. Embora o motor de jogo apresente limitações no processo de simulação da propagação sonora (e por isso evitamos o uso do termo auralização em nossa pesquisa) ele possibilita, como já colocado, a representação de eventos sonoros e sua manipulação, que se relacionam menos à estrutura física da cidade como superfície, e mais ao que ela possibilita acontecer.

A partir desta abordagem, esboçou-se uma ideia de representação da paisagem sonora referente ao ano de 1870. No processo de pesquisa, constatou-se que embora fotografias indicassem como a cidade funcionava em termos programáticos, a compreensão de eventos sonoros e seus comportamentos era de difícil dedução, e encontramos em registros literários descrições relevantes que ajudam a compreender melhor a paisagem da cidade e sua dinâmica.

Uma base teórica importante que auxilia esse tipo de pesquisa é a tese de doutorado de Andrea Rego intitulada "Paisagens sonoras e identidades urbanas: Os sons nas crônicas cariocas e as transformações do bairro de Copacabana (1905 - 1968)". Nessa pesquisa, relatos sonoros foram registrados e categorizados com base em crônicas literárias, identificando sons urbanos relacionados a suas práticas sociais. A obra produzida, mesmo que se trate de Copacabana e apresente um recorte temporal específico, pode ser usada como referência, e juntamente com análises iconográficas e pesquisas documentais fornecem subsídios para possíveis desdobramentos da atual pesquisa.

\section{CONCLUSÕES}

Apresentamos nesse artigo uma metodologia de representação de paisagens sonoras com base em motor de jogo, utilizando o Largo de São Francisco como espaço de experimentação. O protótipo apresentado, longe de ser uma ferramenta concluída, indica caminhos metodológicos a serem explorados e aprimorados, em um contexto em que dois campos explorados - videogames e paisagens sonoras - encontram-se em processo de consolidação.

A ideia da construção de um simulador urbano por meio do motor de jogo amplia o potencial de modelos digitais para outros campos, permitindo representar a experiência por meio do movimento do usuário e dos eventos controlados pelo ambiente de jogo. No caso da mediação sonora, a representação audiovisual de jogos permite ir além dos mapas e outras mídias estáticas e "mudas".

A experimentação prática de se estruturar o ambiente sonoro no motor de jogo trouxe a experiência do "game design" e toda sua complexidade. Nesse processo, o "designer" se torna um "controlador" de forças, relações e comportamentos em um sistema de representação que só se concretiza por meio de interações, e o resultado varia a cada jogo. Essa atitude se contrapõe às técnicas de representação tradicional, que normalmente expressam o resultado final e não o processo em si.

Ao mesmo tempo que o videogame complexifica o olhar sobre o ambiente sonoro, ele possibilita sua redução a signos, variáveis e funções que podem ser programadas e manipuláveis por parâmetros. Isso permite a simulação de cenários diversos, e a criação de "estados" que podem ser investigados e experimentados. A ideia de "estado"

7 
que gera uma possibilidade, foi aqui explorada para a representação de diferentes tempos no simulador, mas pode ser estendida também para a simulação de possibilidades projetuais e cenários hipotéticos.

É importante ressaltar que a metodologia desenvolvida foi um reflexo da compreensão da estrutura do jogo e também das diferentes definições de paisagens sonoras. A procura de regras para o simulador suscitou um novo olhar sobre a dinâmica da cidade e como ela "rege" o ambiente sonoro. A ferramenta desenvolvida derivou deste pensamento e introduziu novas abordagens que podem ser futuramente discutidas.

\section{AGRADECIMENTOS}

Agradecemos ao Comitê Internacional SIGRADI pelas sugestões que contribuíram para a estruturação da base para este modelo, ao Programa de Pós-Graduação em Urbanismo da Universidade Federal do Rio de Janeiro (UFRJ), e à CAPES pela viabilidade financeira.

\section{REFERÊNCIAS}

Aguiar, D. \& Netto, V. (2012) (Org.). Urbanidades. Rio de Janeiro: Folio Digital.

Sisson, R. Espaço e Poder: Os Três Centros do Rio de Janeiro e a Chegada da Corte Portuguesa. (2008). Rio de Janeiro: Arco.

Czajkowski, J. (ED.). (2000) Do Cosmógrafo ao Satélite: Mapas da Cidade do Rio de Janeiro. 1. ed. Rio de Janeiro: Secretaria Municipal de Urbanismo.

Baptista Passos, E., Ricardo da Silva Jr., J., Emiliano Cardoso Ribeiro, F., \& Thiago Mourão, P. ([s.d.]). Tutorial: Desenvolvimento de Jogos com Unity 3D. In SBGames 2009: Pensando na Convergência. Rio de Janeiro.

Vilas Boas, N. (2010). A Construção de Cidades Digitais: Desafios e Estratégias Metodológicas. In I ENANPARQ Arquitetura, Cidade, Paisagem e Território: percursos e prospectivas. Rio de Janeiro.

Collins, K. (2009). An Introduction to Procedural Music in Video Games. Contemporary Music Review, 28(1), 5-15. https://doi.org/10.1080/07494460802663983

Farnell, A. (2007). An introduction to procedural audio and its application in computer games.

Ferreira, A. B. de H. (2004). Dicionário Aurelio Da Lingua Portuguesa (3a). Curitiba: Positivo.

Grimshaw, M. N. (2007). The Acoustic Ecology of the FirstPerson Shooter (Thesis). The University of Waikato. Retrieved https://researchcommons.waikato.ac.nz/handle/10289/2653

Jones, S. (2011). Investigation into modular design within computer games. Staffordshire University, Staffordshire.
Juul, J. (2006). Introduction to Game Time. In N. Wardrip-Fruin \& P. Harrigan (Orgs.), First Person: New Media as Story, Performance, and Game (New Ed edition). Cambridge, Mass.: The MIT Press.

Kang, J., Aletta, F., Gjestland, T. T., Brown, L. A., Botteldooren, D., Schulte-Fortkamp, B., ... Lavia, L. (2016). Ten questions on the soundscapes of the built environment. Building and Environment, 108, 284-294. https://doi.org/10.1016/j.buildenv.2016.08.011

Kós, J. R. (2003). Urban spaces shaped by past cultures: historical representation through electronic 3D models and databases. University Of Strathclyde, Glasgow.

Murphy, D. T., Shelley, S. B., Foteinou, A., Brereton, J. S., \& Daffern, H. (2017). Acoustic Heritage and Audio Creativity: the Creative Application of Sound in the Representation, Understanding and Experience of Past Environments. Internet Archaeology. Retrieved from http://dx.doi.org/10.11141/ia.44.12

Paraizo, R. C. (2009). Patrimônio virtual: representação de aspectos culturais do espaço urbano. Universidade Federal do Rio de Janeiro, Rio de Janeiro.

Rego, A. Q., \& Niemeyer, M. L. (2014). O uso da cartografia sonora na avaliação da transformação das paisagens sonoras devido a implementação do Plano Estratégico Urbano das Vargens - Rio de Janeiro, Brasil. In III ENANPARQ -Arquitetura, cidade e projeto: uma construção coletiva (p. 11). São Paulo.

Rego, A. Q. (2006). (Thesis). Paisagens sonoras e identidades urbanas: os sons nas crônicas cariocas e as transformações do bairro de Copacabana (1905-1968). Universidade Federal do Rio de Janeiro, Rio de Janeiro.

Saldaña, M. (2015). An Integrated Approach to the Procedural Modeling of Ancient Cities and Buildings. Digital Scholarship in the Humanities, 30 (suppl_1), i148-i163. https://doi.org/10.1093/llc/fqv013

Salen, K., \& Zimmerman, E. (2003). Rules of Play: Game Design Fundamentals. Cambridge, Mass: The MIT Press.

Schafer, R. M. (1993). The Soundscape: Our Sonic Environment and the Tuning of the World (Original ed. edition). Destiny Books.

Schum, L. R. (2008). Paisagens Sonoras nos Games. In L. Santaella \& M. Feitoza (Orgs.), Mapa do Jogo (Edição: 1a). São Paulo: Cengage CTP.

Signorelli, V. (2015). Soundwalking in virtual urban ambiances. Applying Game Engine Technologies in soundscape study. Ambiances. Environnement Sensible, Architecture et Espace Urbain, (1). https://doi.org/10.4000/ambiances.657

Southworth, M. F. (1967). The sonic environment of cities. (Thesis). Massachusetts Institute of Technology. Retrieved from http://dspace.mit.edu/handle/1721.1/102214

Truax, B. (1999). Handbook for Acoustic Ecology. Retrieved from https://www.sfu.ca/sonic-studio/handbook/index.html 